\title{
TNF- $\alpha$-mediated upregulation of SOD-2 contributes to cell proliferation and cisplatin resistance in esophageal squamous cell carcinoma
}

\author{
JING ZUO ${ }^{1,2^{*}}$, MEI ZHAO ${ }^{1 *}$, BOWEI LIU ${ }^{1}$, XIAOJING HAN ${ }^{1}$, YUEHONG LI $^{3}$, WEI WANG ${ }^{4}$, \\ QING ZHANG ${ }^{3}$, PING LV ${ }^{5}$, LINGXIAO XING ${ }^{1}$, HAITAO SHEN ${ }^{1}$ and XIANGHONG ZHANG ${ }^{1,3}$
}

${ }^{1}$ Lab of Pathology, Hebei Medical University, Shijiazhuang, Hebei 050017; ${ }^{2}$ Department of Oncology, The Fourth Hospital,

Hebei Medical University, Shijiazhuang, Hebei 050019; ${ }^{3}$ Department of Pathology, The Second Hospital,

Hebei Medical University, Shijiazhuang, Hebei 050000; ${ }^{4}$ Department of Anesthesiology, The Central Hospital of Dandong, Dandong, Liaoning 118002; ${ }^{5}$ Department of Pharmacology, Hebei Medical University, Shijiazhuang, Hebei 050017, P.R. China

Received January 24, 2019; Accepted June 26, 2019

DOI: $10.3892 / o r .2019 .7252$

\begin{abstract}
Intrinsic and acquired resistance of cancer to radio-and chemotherapy is one of the major challenges in the treatment of esophageal squamous cell carcinoma (ESCC). Elevated reactive oxygen species (ROS) play an important role in the resistance to cisplatin in ESCCs. Super dismutase [Mn], mitochondrial (SOD-2), an important primary antioxidant enzyme located in mitochondria, could regulate ROS production. Our previous study showed that tumor necrosis factor- $\alpha$ (TNF- $\alpha$ )-mediated SOD-2 through NF- $\kappa \mathrm{B}$ was involved in epithelial-mesenchymal transition and migration in A549 cells. Therefore, the present study aimed to identify if TNF- $\alpha$ mediated SOD-2 upregulation is involved in cisplatin resistance in ESCC. It was identified that a higher expression of SOD-2 in human ESCC samples was associated with TNF- $\alpha$ expression and poor overall survival in patients with ESCC, suggesting that SOD-2 may act as an oncogene in ESCC. To further confirm if TNF- $\alpha$ could upregulate SOD-2 to contribute to cell proliferation, the human ESCC cell line Eca-109 was treated with TNF- $\alpha$ in vitro. TNF- $\alpha$ could upregulate SOD-2 and induce cell proliferation in Eca109 cells, while blocking SOD-2 using small interfering RNA (siRNA) inhibited TNF- $\alpha$-induced cell proliferation. Upregulation of SOD-2 by TNF- $\alpha$ was inhibited by blocking the NF- $\kappa$ B pathway, which suggested that SOD-2 by TNF- $\alpha / N F-\kappa B$ contributes to cell
\end{abstract}

Correspondence to: Dr Xianghong Zhang or Dr Haitao Shen, Lab of Pathology, Hebei Medical University, 361 East Zhongshan Road, Shijiazhuang, Hebei 050017, P.R. China

E-mail: zhangxianghong2008@163.com

E-mail: haitaoshen78@hotmail.com

${ }^{*}$ Contributed equally

Key words: esophageal squamous cell carcinoma, super dismutase $[\mathrm{Mn}]$, mitochondrial, tumor necrosis factor- $\alpha$, cisplatin resistance proliferation in Eca109 cells. Furthermore, it was observed that TNF- $\alpha$ could induce cisplatin resistance in Eca109 cells, while transfection with SOD-2 siRNA could significantly increase the chemosensitivity of ESCC to cisplatin. Therefore, the present results suggested that SOD-2 may serve as an oncogene, and the upregulation of SOD-2 by TNF- $\alpha / N F-\kappa B$ may contribute to cisplatin resistance in ESCC.

\section{Introduction}

Esophageal squamous cell carcinoma (ESCC) is the major histopathological subtype of esophageal cancer in China, where esophageal cancer is the fourth most common cancer with a total of 477,900 new cases and 375,000 deaths approximated to have occurred in 2015 (1). ESCC is often closely associated with extensive lymphatic and vascular invasion, and early symptoms are usually absent $(2,3)$. At present, the clinical approach to ESCC is surgical treatment combined with radiotherapy and chemotherapy $(4,5)$. However, ESCC still shows a poor prognosis due to high lymphatic metastatic recurrence rates as well as chemotherapy resistance. Intrinsic and acquired resistance of patients with ESCC to radio- and chemotherapy is one of the major challenges in cancer treatment $(4,5)$. Therefore, the 5 year survival rate for patients with ESCC with resectable disease over the past 30 years is $<20 \%$ due to chemotherapy resistance $(2,3)$. A regimen of cisplatin, docetaxel and 5-fluorouracil is recommended as the category 1 treatment for ESCC with distant metastasis, according to the guidelines of The National Comprehensive Cancer Network (5). Cisplatin, a DNA-damaging agent, is widely used as a chemotherapeutic drug for the treatment of various human malignancies, including esophageal cancer (6). However, several series of previous studies have already demonstrated tumor cell resistance to cisplatin both in vivo and in vitro $(5,7,8)$. Therefore, it is very important to identify new biological markers which may predict the response to cisplatin resistance in ESCC.

Several previous studies have found that the mechanisms involved in cisplatin resistance include reduced intracellular 
drug accumulation, increased DNA damage repair, the inhibition of apoptosis, as well as increased generation of reactive oxygen species (ROS) $(6,9)$. Elevated ROS are found in all cisplatin-resistant cell lines, including those derived from patients who did not respond to cisplatin treatment (9). Mitochondria are the organelles where the majority of cellular ROS are generated and play a central role in ROS-mediated apoptosis (10). Super dismutase [Mn], mitochondrial (SOD-2), an important primary antioxidant enzyme located in mitochondria, plays a vital role in ROS metabolism in that it converts highly toxic superoxide $\left(\mathrm{O}_{2}{ }^{\bullet-}\right)$ into less toxic hydrogen peroxides $\left(\mathrm{H}_{2} \mathrm{O}_{2}\right)$ in the mitochondria, a site that is vulnerable to ROS attack and important to cell apoptosis $(11,12)$. As part of the nucleoid complex, SOD-2 may protect mitochondrial DNA (mtDNA) from ROS-mediated damage by interacting with Pol $\gamma$, glutathione peroxidase, and mtDNA itself (13). Zhou and Du (14) reported that acquisition of resistance in pancreatic cancer cells to 2-methoxyestradiol is associated with the upregulation of SOD-2. Those previous studies suggested that SOD-2 and ROS may play an important role in cisplatin resistance during tumor chemotherapy $(13,14)$. However, whether SOD-2 contributes to cell proliferation and cisplatin resistance in ESCC is unknown, and needs to be investigated further.

Our recent study indicated that tumor necrosis factor- $\alpha$ (TNF- $\alpha$ )-mediated SOD-2 upregulation through the NF- $\kappa \mathrm{B}$ pathway plays an important role in epithelial-mesenchymal transition (EMT) and migration in A549 cells (15). Chung-man Ho et al (16) reported that TNF- $\alpha$ upregulated SOD-2 in A549 cells, which suggested that inflammation in the lung tissues may contribute to high levels of manganese SOD and decreased catalase, hence creating an intracellular environment favorable to DNA damage and the promotion of cancer. Kinugasa et al (17) reported that the NF- $\kappa \mathrm{B}$ pathway contributes to SOD-2 upregulation in well-defined transformed oral and esophageal human epithelial cell lines. These findings support that the TNF- $\alpha$-mediated $N F-\kappa B$ pathway may play a critical role in regulating SOD-2 expression in tumor cells. Therefore, the present study examined whether TNF- $\alpha$ mediated SOD-2 upregulation is involved in cisplatin resistance in ESCC.

\section{Materials and methods}

Materials. Rabbit anti-nuclear factor (NF)- $\kappa \mathrm{B} / \mathrm{p} 65$ (cat. no. 1546-1) and rabbit anti-SOD-2 (cat. no. 2299-s) antibodies were purchased from Epitomics; Abcam. Rabbit anti-phosphorylated (p)-NF- $\mathrm{B} / \mathrm{p}-\mathrm{p} 65$ (cat. no. 3033P) and Survivin (cat. no. 2808) antibodies were purchased from Cell Signaling Technology, Inc. CyclinD1 (cat. no. ab134175) and rabbit anti-Bax (cat. no. ab32503) antibodies were purchased from Abcam. Histone H3 (cat. no. AF0863) antibody was purchased from Affinity Biosciences. $\beta$-actin (cat. no. AC026) antibody was purchased from ABclonal Biotech Co., Ltd. Peroxidase-labeled anti-rabbit IgG secondary antibody (cat. no. 074-1506) and anti-mouse IgG secondary antibody (cat. no. 074-1806) were purchased from KPL, Inc. Cytokine TNF- $\alpha$ was purchased from Peprotech, Inc. Cisplatin was purchased from Qilu Pharmaceutical Co., Ltd.
Human ESCC samples. Paraffin-embedded human ESCC cancer samples were obtained from The Department of Pathology, Second Hospital of Hebei Medical University between January 2010 and July 2014. A total of 60 cases of ESCC and 30 cases of paired adjacent non-cancerous normal esophageal tissues (from $>2 \mathrm{~cm}$ away from the tumor margin) were obtained in the present study. All 60 patients (44 male and 16 female) were $<75$ years of age, and were diagnosed before chemotherapy, radiotherapy or other treatments. The patients, who agreed to the use of their samples in scientific research, all provided written informed consent. The present study was approved by the Ethics Committee of Hebei Medical University (Hebei, China), and the handling of the information and specimens collected was conducted in accordance with their ethical and legal standards. Diagnosis of ESCC was performed by two specialized pathologists based on the criteria stipulated by the World Health Organization $(18,19)$. The TNM stage of ESCC was based on the 8th Edition American Joint Committee on Cancer/Union for International Cancer Control staging manuals (18). The clinical histopathological data of the patients and the overall survival information of the patients are available until death or the end of the investigation.

Immunohistochemical staining. Paraffin-embedded human ESCC samples were collected. All samples were sectioned to $5 \mu \mathrm{m}$ thickness and immunohistochemically stained, as previously described (20). Briefly, after blocking, the sections were incubated with antibodies against TNF- $\alpha$, SOD-2, CyclinD1 and Survivin $(1: 200)$ overnight at $4^{\circ} \mathrm{C}$. Visualization was achieved with peroxidase-labeled streptavidin-biotin $(1 \mathrm{~h}$ at room temperature) and diaminobenzidine (2-5 $\mathrm{min}$ at room temperature) staining. Positive cells were observed under a light microscope (magnification, x200).

The degree of immunostaining was scored independently by two specialized pathologists, according to a previous study (21). Briefly, the proportion of tumor cells was scored as: i) 0 (no positive tumor cells); ii) 1 ( $<30 \%$ positive tumor cells), iii) 2 (30-60\% positive tumor cells); and iv) 3 ( $>60 \%$ positive tumor cells). The intensity of staining was graded as: i) 0 (for no staining); ii) 1 (weak staining, light yellow); iii) 2 (moderate staining, yellow brown); and iv) 3 (strong staining, brown). The final staining index was calculated as the staining intensity score times the proportion of positive tumor cells, and scores $\leq 4$ were defined as low expression of SOD-2.

Cell culture and treatment. Human Eca109 cells and OE-21 cells were obtained from The Resource Center of Peking Union Medical College Hospital of China. Eca109 and OE-21 cells were maintained in RPMI 1640 medium containing 10\% FBS (both Gibco; Thermo Fisher Scientific, Inc.). and penicillin/streptomycin, at $37^{\circ} \mathrm{C}$ and in a $5 \% \mathrm{CO}_{2}$ humidified atmosphere. The expression of SOD-2 was measured by western blotting. Cells ( $1 \times 10^{5}$ cells/well) were seeded into 6-well plates. Transfections were carried out using Lipofectamine ${ }^{\circledR} 2000$ reagent (Invitrogen; Thermo Fisher Scientific, Inc.) according to the manufacturer's protocol. The control small interfering RNA (siRNA), SOD-2 siRNAs and NF- $\kappa$ B siRNAs were obtained from Shanghai GenePharma Co., Ltd. The siRNA sequences are presented in Table I. The cells were cultured 
Table I. siRNA sequences.

SiRNA

Forward, 5'-3'

Reverse, 3'-5'

$\begin{array}{ll}\text { Control siRNA } & \text { UUCUCCGAACGUGUCACGUTT } \\ \text { NF- } \kappa \text { B siRNA } & \text { CGCCAUCUAUGACAGUAAATT } \\ \text { SOD-2 siRNA } & \text { GGGUUGGCUUGGUUUCAAUTT }\end{array}$

ACGUGACACGUUCGGAGAATT UUUACUGUCAUAGAUGGCGTT AUUGAAACCAAGCCAACCCTT

siRNA, small interfering RNA; SOD-2, super dismutase [Mn], mitochondrial.

for $24 \mathrm{~h}$ to allow for successful knockdown, then the cells transfected with $0.05 \mu \mathrm{M}$ control siRNA, SOD-2 siRNAs or $\mathrm{NF}-\kappa \mathrm{B}$ siRNAs were treated with TNF- $\alpha(20 \mathrm{ng} / \mathrm{ml})$ for $24 \mathrm{~h}$, according to the design of each experiment.

In some experiments, the cells were re-treated with different concentrations of cisplatin for $24 \mathrm{~h}$, and cell death and apoptosis were measured.

RNA isolation and reverse transcription-quantitative PCR. After treatment, the Eca109 cells were homogenized with TRIzol ${ }^{\circledR}$ reagent (Invitrogen; Thermo Fisher Scientific,Inc.) and total RNA of cells was isolated using an RNeasy-kit (Qiagen $\mathrm{GmbH}$ ) according to the manufacturer's protocol (15). The total RNA was reverse transcribed to cDNA in a total volume of $20 \mu \mathrm{l}$ using a reaction mixture kit (Promega Corporation). The RT temperature protocol was as follows: Start for $10 \mathrm{~min}$ at $25^{\circ} \mathrm{C}, 1 \mathrm{~h}$ at $42^{\circ} \mathrm{C}, 10 \mathrm{~min}$ at $80^{\circ} \mathrm{C}$, and then the reaction stopped at $4^{\circ} \mathrm{C}$. Transcript levels of SOD-2 were evaluated by RT-qPCR using a SYBR Green kit (Promega Corporation). The PCR thermocycling conditions included: $10 \mathrm{~min}$ at $95^{\circ} \mathrm{C}$ followed by 40 cycles of denaturation for $15 \mathrm{sec}$ at $95^{\circ} \mathrm{C}$, and annealing for $1 \mathrm{~min}$ at $60^{\circ} \mathrm{C}$. Gene expression was normalized against the housekeeping gene $\beta$-actin. The following primers were used: SOD-2 primer: Forward 5'-3'CACTGCAAGGAA CAACAGGC, reverse 3'-5'ACCAGGCTTGATGCACAT CTT; and $\beta$-actin primer: Forward 5'-3'AGCGAGCATCCC CCAAAGTT, reverse 3'-5'GGGCACGAAGGCTCATCATT. Relative gene expression was calculated using the comparative $2^{-\Delta \Delta \mathrm{Cq}}$ method (22).

Western blotting. After treatment, the Eca109 cells were harvested and homogenized in $100 \mu \mathrm{l}$ lysis buffer $(10 \mu \mathrm{l}$ Tris $\mathrm{HCl} \mathrm{pH} 7.5 ; 15 \mu \mathrm{l} 1 \mathrm{M} \mathrm{NaCl} ; 10 \mu \mathrm{l}$ EDTA pH 8.0; $1 \mu \mathrm{l}$ Tritanx-100; $\left.64 \mu \mathrm{l} \mathrm{ddH}_{2} \mathrm{O}\right)$. Total protein was extracted by centrifuging at $10,625 \mathrm{x}$ g for $30 \mathrm{~min}$ at $4^{\circ} \mathrm{C}$. To detect nuclear translocation of $\mathrm{NF}-\kappa \mathrm{B}$ p 65 , the nuclear proteins were extracted using a Thermo Scientific Pierce NE-PER kit (Thermo Fisher Scientific, Inc.). Protein concentrations were determined using a standard bicinchoninic acid assay kit (Thermo Fisher Scientific, Inc.). Then, 30-100 $\mu \mathrm{g}$ protein per sample was separated by SDS-PAGE on $10 \%$ gels, and transferred to PVDF nylon membranes. After blocking with 5\% non-fat milk in TBS and Tween-20 for $2 \mathrm{~h}$ at room temperature, the membranes were incubated with NF- $\kappa \mathrm{B}$ p65, CyclinD1, Survivin and SOD-2 antibodies $(1: 1,000)$ or Bax $(1: 500)$ at $4^{\circ} \mathrm{C}$ overnight. The membranes were incubated with the antibody against $\beta$-actin (ABclonal Biotech Co., Ltd.) at $4^{\circ} \mathrm{C}$ overnight, which was used as the control. The membranes were incubated with p-NF- $\kappa \mathrm{B}$ p65 and histone $\mathrm{H} 3(1: 1,000)$ at $4^{\circ} \mathrm{C}$ overnight. Histone $\mathrm{H} 3$ was used as the loading control for nuclear fraction. The membranes were then washed and incubated with anti-rabbit IgG secondary antibody $(1: 2,000)$ or anti-mouse IgG secondary antibody labeled with peroxidase $(1: 5,000)$ for $1.5 \mathrm{~h}$ at $37^{\circ} \mathrm{C}$. The protein signals were acquired using Pierce ECL Western Blotting Substrate (Thermo Fisher Scientific, Inc.) and an ECL detection system. The resulting images were quantified by densitometric analysis using BIO-1D 11.0 software [Gold Sim (Beijing) International Co.].

Cell Counting Kit-8 (CCK-8) assay. Eca109 cells $\left(2 \times 10^{4} / \mathrm{ml}\right)$ were seeded into 96 -well plates and treated with or without TNF- $\alpha$ for $24 \mathrm{~h}$. The cells transfected with negative control-siRNA or SOD-2 siRNA were treated with different concentrations $(1,2,4,8,16$ and $32 \mu \mathrm{g} / \mathrm{ml})$ of cisplatin for $24 \mathrm{~h}$, according to the design of experiments. Cell death was measured by a CCK-8 assay (MedChemExpress), according to the manufacturer's protocol. Experiments were carried out at least three times.

Colony formation assay. After Eca109 cells were transfected with control siRNA or SOD-2 siRNA, the cells were counted and seeded (2,000 cells/well) in 96-well plates. The cells were treated with TNF- $\alpha$ and fresh culture medium containing TNF- $\alpha$ was replaced every 3 days. The number of colonies was counted at 9-12 days when the colonies contained $>50$ cells. The cells were fixed with $10 \%$ formalin for $1 \mathrm{~h}$ at room temperature and stained with crystal violet for $8 \mathrm{~min}$ at room temperature. Colony formation ability was determined by colony formation number. Cell numbers were counted under a light microscope (magnification, x50). Experiments were repeated at least three times.

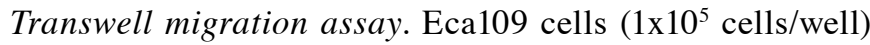
were plated in medium without serum in the top chamber of a transwell plate (Corning, Inc.). The bottom chamber contained standard medium with $10 \%$ FBS plus TNF- $\alpha$. After $48 \mathrm{~h}$ of incubation, the cells in the top chamber had migrated to the lower surface of the membrane, were then fixed with $10 \%$ formalin for $1 \mathrm{~h}$ at room temperature, stained with crystal violet for $8 \mathrm{~min}$ at room temperature, and imaged under a microscope. Cell numbers in the bottom chamber were counted under a light microscope (magnification, x400). Experiments were carried out at least three times.

Flow cytometric analysis. After treatment with a low concentration of cisplatin $(2 \mu \mathrm{g} / \mathrm{ml})$, Eca109 cells were harvested 

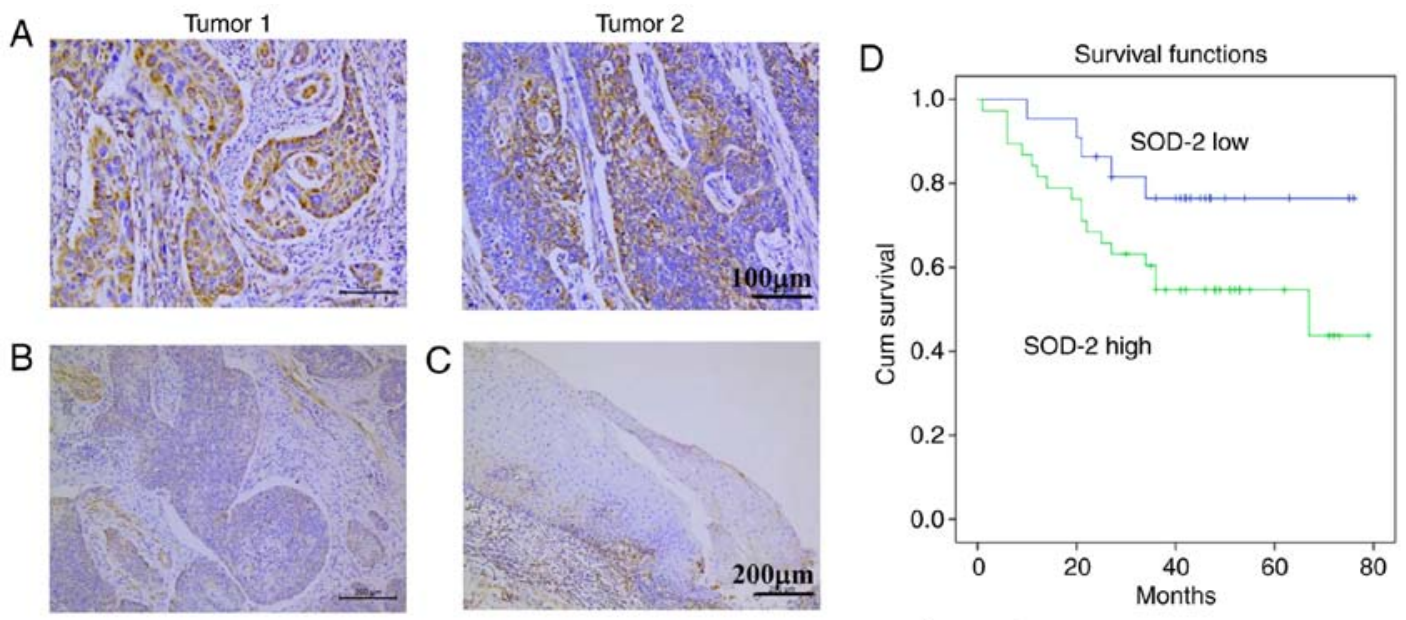

$\chi^{2}=3.757 \mathrm{P}=0.056$

Figure 1. Expression of SOD-2 in human ESCC samples. Representative immunohistochemistry images show (A) positive expression of SOD-2 in ESCC, and (B) negative expression of SOD-2 in ESCC and (C) adjacent non-cancerous tissue. (D) Kaplan-Meier analysis was used to plot the overall survival curves of 60 cases of ESCC with SOD-2 high expression or low expression. SOD-2, super dismutase [Mn], mitochondrial; ESCC, esophageal squamous cell carcinoma

and stained with PE Annexin V and propidium iodide (PI) kit (BD Biosciences), according to the manufacturer's protocol. The cell apoptosis rates were measured by fluorescence-activated cell sorting analysis using a flow cytometer, according to our previous study (23). Briefly, Eca109 cells were stained with $5 \mu \mathrm{l}$ Annexin V for $15 \mathrm{~min}$ and then $5 \mu \mathrm{l}$ PI for $5 \mathrm{~min}$ at room temperature in the dark. Both early apoptotic cells (Annexin V-positive and PI-negative) and late apoptotic cells (Annexin V-positive and PI-positive) were included in apoptosis rate determinations. The data was analyzed using FlowJo software 7.6 (FlowJo, LLC). Experiments were carried out at least three times.

Statistical analysis. Statistics were calculated using SPSS 21.0 software (IMB, Corp.). Associations between SOD-2 expression and clinical pathologic characteristics were assessed with $\chi^{2}$ test. Spearman's correlation analysis was applied to determine the relationship between SOD-2 and TNF- $\alpha$ expression as well as CyclinD1 and Survivin in ESCC samples. Overall survival was measured from the date of surgical operation to the date of death, or the last clinical follow-up time before November 2016, according to the Kaplan-Meier method. The log-rank test was used to compare the survival distribution. $\mathrm{P}<0.05$ was considered to indicate a statistically significant difference.

One-way ANOVA or two-way ANOVA was applied according to one or two variables in the present study in vitro. When there was a significant ANOVA result, post-hoc analysis was performed using the Least Significant Difference test to assess multiple comparisons. Data are presented as the mean \pm SD of at least three independent experiments. $\mathrm{P}<0.05$ was considered to indicate a statistically significant difference.

\section{Results}

Increased expression of SOD-2 in human esophageal squamous cell carcinoma. Human ESCC samples were collected and the expression of SOD-2 in ESCC as well as its role in the overall survival of patients with ESCC was analyzed. In total, 60 cases of ESCC were collected and the expression of SOD-2 was detected by immunohistochemical staining. After blinding the identity of the tissue sections, high expression of SOD-2 was observed in the cytoplasm of some human ESCC cells (Fig. 1A). Low expression of SOD-2 was also observed in some human ESCC cells (Fig. 1B) as well as normal esophageal epithelial cells (Fig. 1C). Of the 60 ESCC cases, 38 (63.3\%) stained positively for SOD-2 with higher expression of SOD-2 compared with normal esophageal epithelial cells (Table II). Kaplan-Meier analysis indicated that higher expression of SOD-2 was associated with a poor overall survival in patients with ESCC (Fig. 1D; P=0.056). To further explore the role of SOD-2 in human ESCC, the association between SOD-2 and clinical parameters, including age, sex, differentiation and TNM stage in 60 cases of human ESCC was assessed. It was determined that high expression of SOD-2 was significantly associated with lymph node metastasis and TNM stage in the patients, but was not associated with other clinical features, such as age, sex and tumor differentiation of patients (Table III).

Furthermore, the correlation between TNF- $\alpha$ and SOD-2, CyclinD1, and Survivin in ESCC samples was analyzed. Immunohistochemical staining determined the expression of TNF- $\alpha$, SOD-2, CyclinD1 and Survivin in the same ESCC samples (Fig. 2). Positive TNF- $\alpha$ expression was highly correlated with SOD-2, CyclinD1 and Survivin expressions (Table IV), while positive SOD-2 expression was significantly correlated with CyclinD1 and Survivin expressions in human ESCC samples (Table V). The present results suggested that increased SOD-2 in ESCC may be correlated with TNF- $\alpha$ expression, as well as proliferation-related proteins CyclinD1 and Survivin, which suggested that TNF- $\alpha$ may regulate SOD-2, contributing to cell proliferation in ESCC.

$T N F-\alpha$ induces cell proliferation associated with upregulation of SOD-2 expression in human ESCC. The human ESCC cell line Eca-109 was treated with TNF- $\alpha$ to determine if TNF- $\alpha$ contributes to SOD-2 expression in ESCC in vitro. It was determined that a low concentration of TNF- $\alpha$ could significantly increase cell viability and colony formation in Eca109 cells, which suggests that TNF- $\alpha$ could induce cell 
Table II. Positive rate of SOD-2 expression.

\begin{tabular}{lcccc}
\hline & & \multicolumn{2}{c}{ SOD-2 expression } & \\
\cline { 3 - 4 } Groups & $\mathrm{n}$ & Low (\%) & High (\%) & P-value \\
\hline Normal & 30 & $6(20)$ & $24(80)$ & $<0.05$ \\
Cancer & 60 & $38(63.3)$ & $22(36.7)$ & \\
\hline
\end{tabular}

$\chi^{2}$ test. SOD-2, super dismutase [Mn], mitochondrial.

Table III. SOD-2 expression and clinicopathological characteristics in 60 cases of esophageal squamous cell carcinoma.

\begin{tabular}{|c|c|c|c|c|}
\hline \multirow[b]{2}{*}{ Clinicopathological variables } & \multirow[b]{2}{*}{$\mathrm{n}$} & \multicolumn{2}{|c|}{$\begin{array}{c}\text { SOD-2 } \\
\text { expression }\end{array}$} & \multirow[b]{2}{*}{ P-value } \\
\hline & & Low & High & \\
\hline Age (years) & & & & 0.492 \\
\hline$\leq 60$ & 16 & 7 & 9 & \\
\hline$>60$ & 44 & 15 & 29 & \\
\hline Sex & & & & 0.815 \\
\hline Female & 18 & 7 & 11 & \\
\hline Male & 42 & 15 & 27 & \\
\hline Differentiation & & & & 0.184 \\
\hline Well/moderate & 43 & 18 & 25 & \\
\hline Poor & 17 & 4 & 13 & \\
\hline Lymph node metastasis & & & & 0.019 \\
\hline Negative & 29 & 15 & 14 & \\
\hline Positive & 31 & 7 & 24 & \\
\hline TNM stage & & & & 0.02 \\
\hline I & 11 & 8 & 3 & \\
\hline II & 25 & 8 & 17 & \\
\hline III & 24 & 6 & 18 & \\
\hline
\end{tabular}

$\chi^{2}$ test. SOD-2, super dismutase [Mn], mitochondrial.

proliferation in ESCC (Fig. 3A-C; $\mathrm{P}<0.05$ ). It was additionally identified that TNF- $\alpha$ could enhance cell migration in Eca-109 cells (Fig. 3D and E; $\mathrm{P}<0.05$ ). The western blotting results indicated that TNF- $\alpha$ upregulated SOD-2 as well as CyclinD1 and Survivin expressions in Eca-109 cells (Fig. 3F and G). Additionally, it was observed that Bax was significantly downregulated in cells treated with TNF- $\alpha$ (Fig. $3 F$ and G). These results suggested that TNF- $\alpha$ induces cell proliferation associated with upregulation of SOD-2 in human ESCC cells.

TNF- $\alpha$ upregulates SOD-2 through the NF- $\kappa B$ pathway to induce cell proliferation in human ESCC. To further explore whether upregulation of SOD-2 plays a critical role in TNF- $\alpha$-induced cell proliferation in human ESCC, SOD-2 expression was blocked by transfecting cells with SOD-2 siRNA (Fig. 4A). It was observed that blocking SOD-2

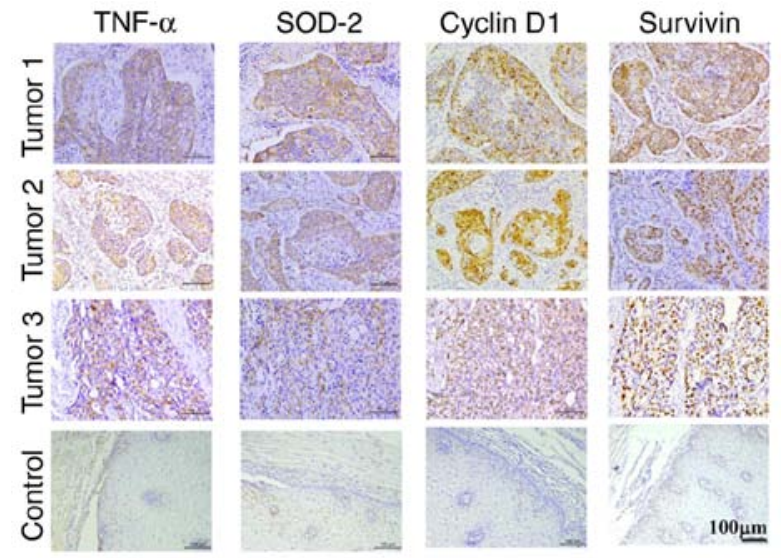

Figure 2. Association between SOD-2 and TNF- $\alpha$, CyclinD1, and Survivin in human ESCC samples. The images from immunohistochemical staining show the co-expression of SOD-2 and TNF- $\alpha$, CyclinD1 and Survivin in human ESCC samples as well as adjacent non-cancerous tissue. ESCC, esophageal squamous cell carcinoma. SOD-2, super dismutase [Mn], mitochondrial; TNF- $\alpha$, tumor necrosis factor- $\alpha$.

expression significantly inhibited TNF- $\alpha$-elevated cell viability and colony formation in ESCC cells (Fig. 4B-D; $\mathrm{P}<0.05)$. As shown in Fig. $4 \mathrm{~B}$ and $\mathrm{D}$, the cell viability and colony formation in ESCC cells were also inhibited by SOD-2 siRNA, which suggested that SOD-2 may play a critical role in cell proliferation in ESCC. Furthermore, blocking SOD-2 expression significantly inhibited TNF- $\alpha$-induced cell migration in ESCC cells (Fig. 4E and F; P<0.05). Increased CyclinD1 and Survivin levels induced by TNF- $\alpha$ were also inhibited in Eca109 cells transfected with siRNA (Fig. 4G and $\mathrm{H}$; $\mathrm{P}<0.05$ ). These results suggested that upregulation of SOD-2 by TNF- $\alpha$ contributes to cell proliferation in Eca109 cells. To further explore the mechanism of upregulated-SOD-2 by TNF- $\alpha$ in Eca-109 cells, the NF- $\mathrm{B}$ pathway downstream of TNF- $\alpha$ was blocked by siRNA. It was identified that blocking the NF- $\kappa$ B pathway by siRNA significantly inhibited TNF- $\alpha$-increased cell migration in Eca109 cells (Fig. 4I and J; P<0.05). Increased SOD-2 as well as CyclinD1 and Survivin induced by TNF- $\alpha$ was inhibited in Eca109 cells transfected with NF- $\mathrm{B}$ siRNA (Fig. 4K and $\mathrm{L} ; \mathrm{P}<0.05$ ). Therefore, the present data suggested that TNF- $\alpha$ could upregulate SOD-2 through the NF- $\kappa$ B pathway to contribute to cell proliferation in Eca109 cells.

SOD-2 affects the chemosensitivity of ESCC to cisplatin. Since upregulation of SOD-2 by TNF- $\alpha$ contributes to cell proliferation and migration in Eca109 cells, the present study investigated whether TNF- $\alpha$ induces cisplatin resistance, as well as the role of SOD-2 in the chemosensitivity of ESCC to cisplatin. It was observed that TNF- $\alpha$ increased cisplatin resistance over a range of concentrations $(4-32 \mu \mathrm{g} / \mathrm{ml})$ in the NC siRNA group, while SOD-2 blocking enhanced cisplatin chemosensitivity over a range of concentrations $(1-32 \mu \mathrm{g} / \mathrm{ml})$ in ESCC cells transfected with SOD-2 siRNA compared with the NC siRNA group (Fig. 5A; $\mathrm{P}<0.05$ ). Transfection with SOD-2 siRNA significantly increased the chemosensitivity of ESCC to cisplatin $(4-32 \mu \mathrm{g} / \mathrm{ml})$ in TNF- $\alpha$-induced Eca-109 cells compared with the TNF- $\alpha+N C$ siRNA group (Fig. 5A; $\mathrm{P}<0.05$ ). The $\mathrm{IC}_{50}$ of cisplatin in $\mathrm{TNF}-\alpha$-induced Eca-109 cells was higher than that in the control cells (Fig. 5B; 
Table IV. Correlation between TNF- $\alpha$ with CyclinD1, Survivin as well as SOD-2.

\begin{tabular}{|c|c|c|c|c|c|c|c|c|c|c|c|c|}
\hline \multirow[b]{2}{*}{ TNF- $\alpha$} & \multicolumn{4}{|c|}{ CyclinD1 } & \multicolumn{4}{|c|}{ Survivin } & \multicolumn{4}{|c|}{ SOD-2 } \\
\hline & High & Low & $\mathrm{r}$ & P-value & High & Low & $\mathrm{r}$ & P-value & High & Low & $\mathrm{r}$ & P-value \\
\hline 39 (high) & 31 & 8 & 0.499 & $<0.001$ & 34 & 5 & 0.293 & 0.023 & 33 & 6 & 0.602 & $<0.05$ \\
\hline 21 (low) & 6 & 15 & & & 13 & 8 & & & 5 & 16 & & \\
\hline
\end{tabular}

TNF- $\alpha$, tumor necrosis factor- $\alpha$; SOD-2, super dismutase [Mn], mitochondrial.

Table V. Correlation between SOD-2 with CyclinD1 as well as Survivin.

\begin{tabular}{|c|c|c|c|c|c|c|c|c|}
\hline \multirow[b]{2}{*}{ SOD-2 } & \multicolumn{4}{|c|}{ CyclinD1 } & \multicolumn{4}{|c|}{ Survivin } \\
\hline & High & Low & $\mathrm{r}$ & $\mathrm{P}$-value & High & Low & $\mathrm{r}$ & P-value \\
\hline 38 (high) & 30 & 8 & 0.681 & $<0.001$ & 31 & 7 & 0.291 & 0.036 \\
\hline 22 (low) & 7 & 15 & & & 16 & 6 & & \\
\hline
\end{tabular}

SOD-2, super dismutase [Mn], mitochondrial.
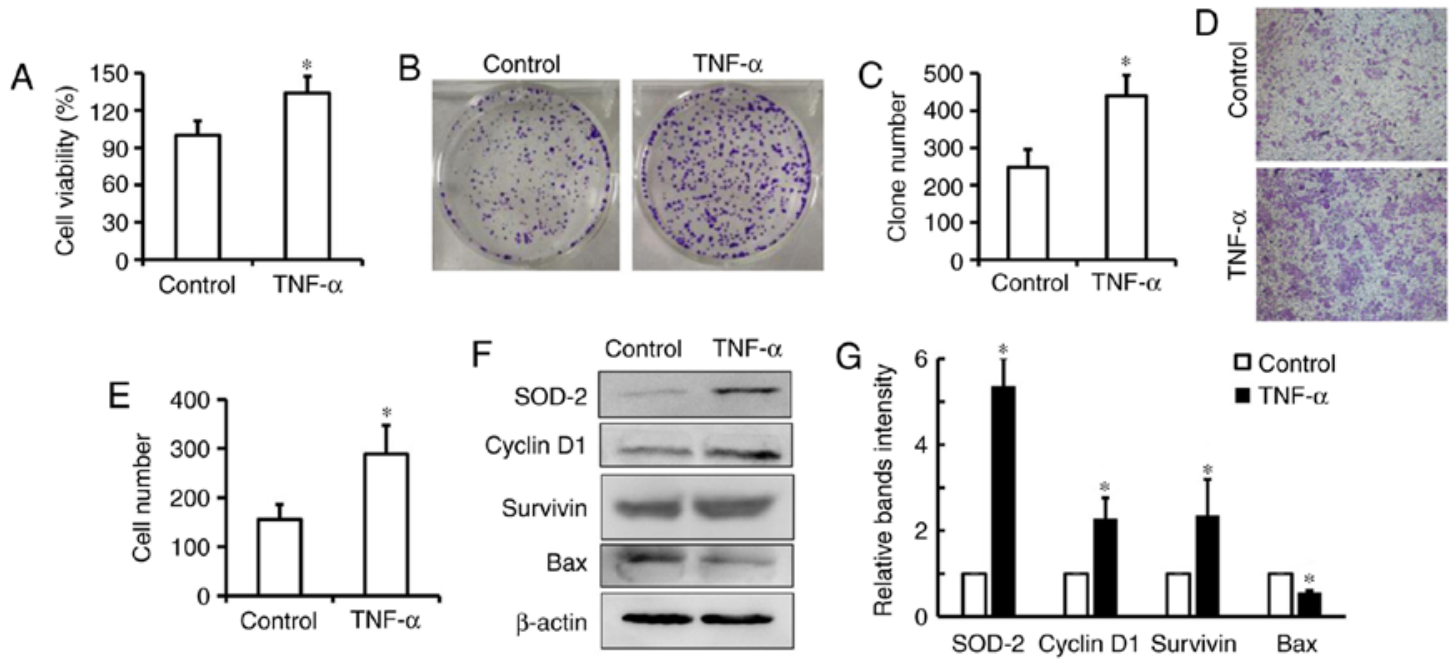

Figure 3. TNF- $\alpha$ induces cell proliferation in esophageal cancer cells. (A) Eca109 cells were treated with $20 \mathrm{ng} / \mathrm{ml} \mathrm{TNF}-\alpha$ for $24 \mathrm{~h}$, and cell proliferation was measured by a Cell Counting Kit- 8 assay. (B and C) After $20 \mathrm{ng} / \mathrm{ml}$ TNF- $\alpha$-treatment for $9-12$ days, colony formation was counted and the number was represented as percent of total cells at the beginning of the assay. (D and E) After $20 \mathrm{ng} / \mathrm{ml} \mathrm{TNF-} \alpha$-treatment for $48 \mathrm{~h}$, the migratory ability of Eca109 cells was measured by a transwell migration assay and the cell number was determined by counting the number of positive cells in the higher field. Magnification, $\mathrm{x} 400$. After $20 \mathrm{ng} / \mathrm{ml} \mathrm{TNF}-\alpha$-treatment for $24 \mathrm{~h}$, the expression of CyclinD1, Survivin, SOD-2 and Bax was measured by (F) western blotting and (G) densitometric analysis. Data are presented as the mean \pm SD of three independent experiments. ${ }^{*} \mathrm{P}<0.05$ vs. respective control. TNF- $\alpha$, tumor necrosis factor- $\alpha$; SOD- 2 , super dismutase $[\mathrm{Mn}]$, mitochondrial.

$\mathrm{P}<0.05)$. However, transfection with SOD-2 siRNA significantly decreased the $\mathrm{IC}_{50}$ of cisplatin both in $\mathrm{TNF}-\alpha$-induced Eca-109 cells and control cells (Fig. 5B; $\mathrm{P}<0.05$ ). Therefore, it was demonstrated that SOD-2 contributes to TNF- $\alpha$-induced cisplatin resistance in ESCC.

Furthermore, in order to confirm that SOD-2 contributes to cisplatin resistance in Eca-109 cells, the effect of a low concentration of cisplatin on the apoptosis rate of Eca-109 cells transfected with SOD-2 siRNA was determined. It was identified that $2 \mu \mathrm{g} / \mathrm{ml}$ cisplatin did not induce apoptosis in Eca-109 cells but could cause apoptosis in cells transfected with SOD-2 siRNA (Fig. 5C and D; $\mathrm{P}<0.05$ ). Therefore, the present results suggested that inhibition of SOD-2 significantly increases the chemosensitivity of ESCC to cisplatin, which suggested that SOD-2 may play a critical role in cisplatin resistance in ESCC.

\section{Discussion}

SOD-2, located in the mitochondria, is the major antioxidant enzyme in the regulation of oxidative stress, and it functions 
A
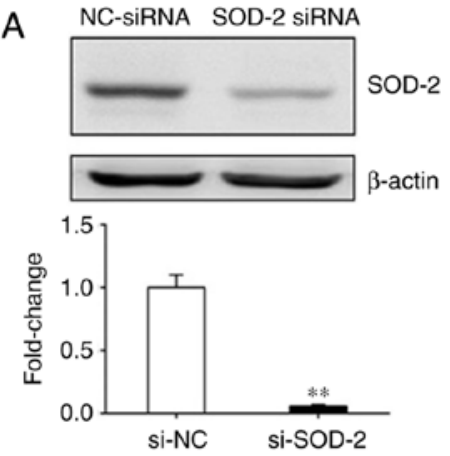

D

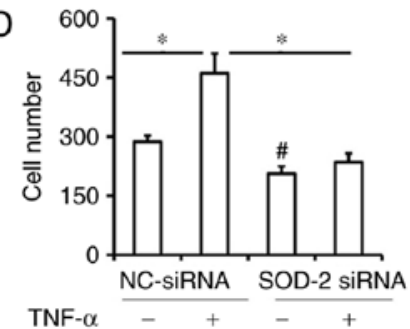

E

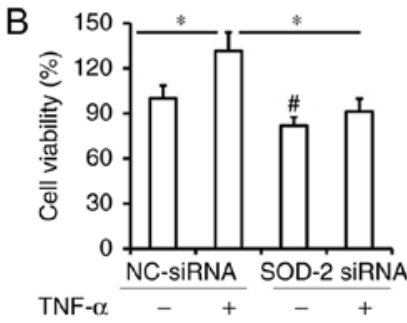

C
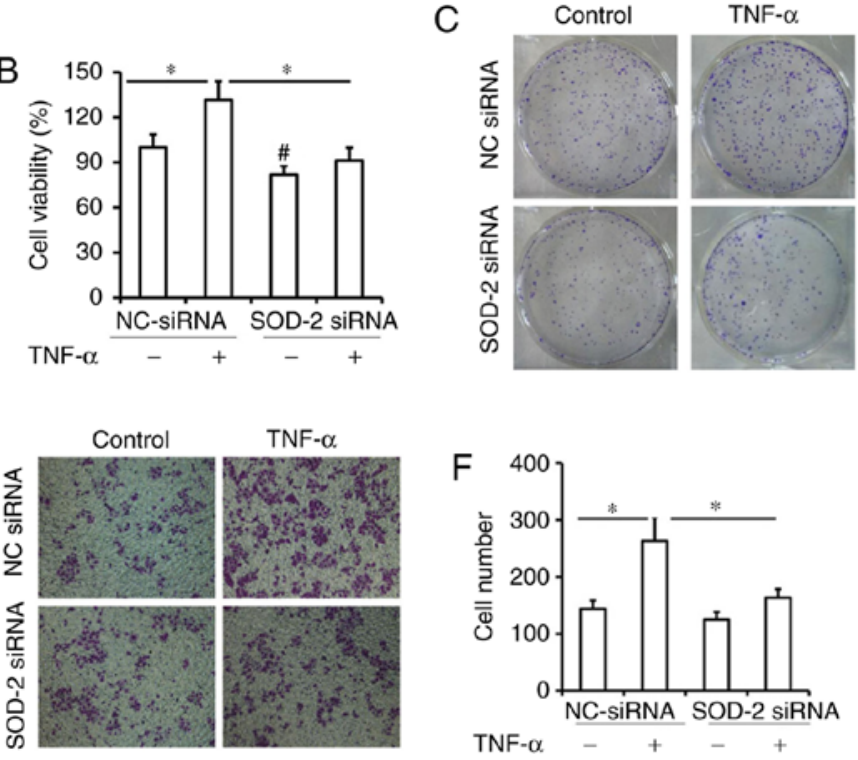

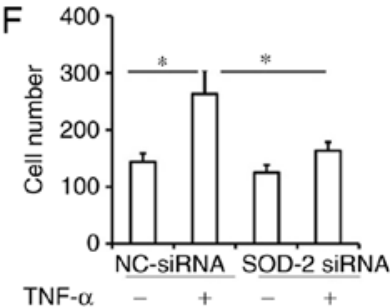

$\mathrm{TNF}-\alpha+\ldots+$
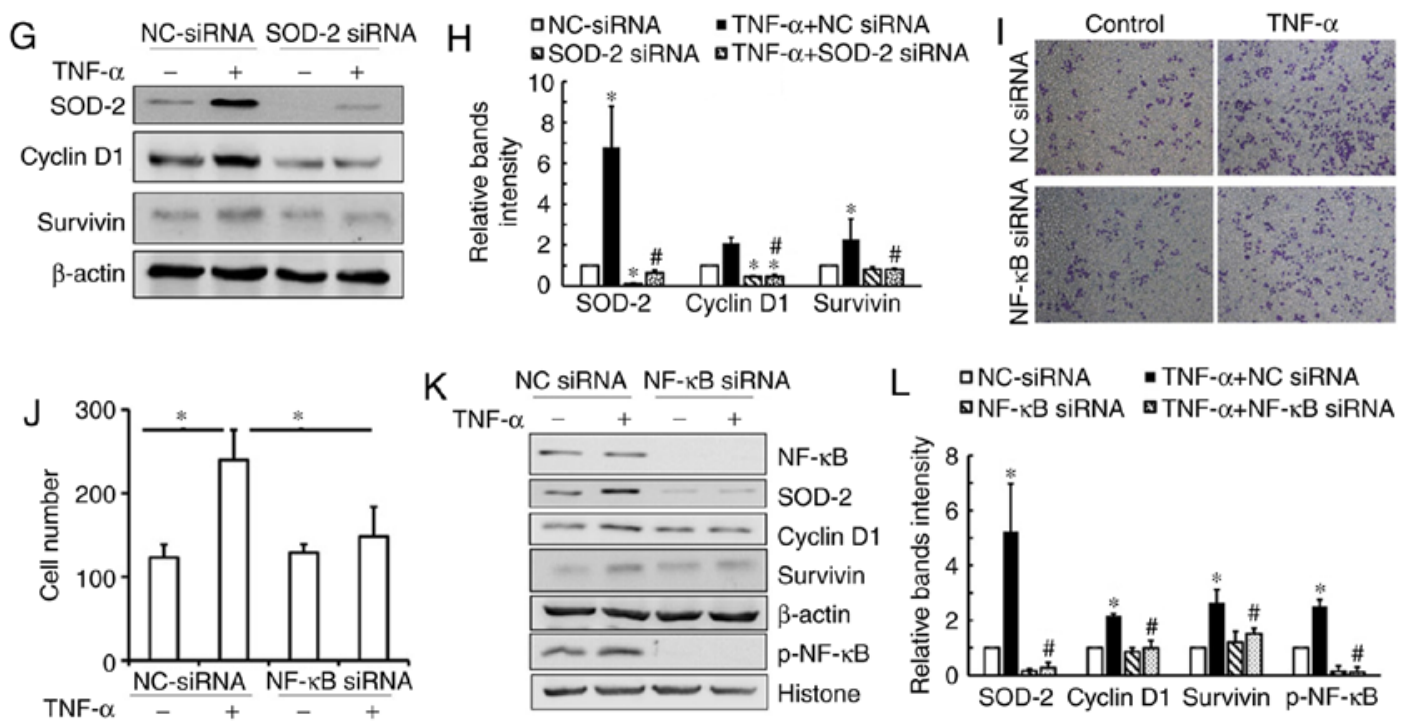

Figure 4. SOD-2 contributes to TNF- $\alpha$-induced proliferation in esophageal cancer cells through the NF-kB pathway. (A) Expression of SOD-2 mRNA and protein levels was significantly inhibited after transfection with SOD-2 siRNA in Eca109 cells. Eca109 cells were transfected with SOD-2 siRNA or control siRNA, and then treated with $20 \mathrm{ng} / \mathrm{ml} \mathrm{TNF-} \alpha$. ${ }^{* *} \mathrm{P}<0.01 \mathrm{vs}$. si-NC. (B) After TNF- $\alpha$-treatment for $24 \mathrm{~h}$, cell proliferation in both cell samples were measured by a Cell Counting Kit- 8 assay. ${ }^{*} \mathrm{P}<0.05 ;{ }^{~} \mathrm{P}<0.05$ vs. NC-siRNA. (C and D) After treatment for $9-12$ days, colony formation was also assessed, and the number is represented as percent of total cells at the beginning of the assay. ${ }^{~} \mathrm{P}<0.05$; ${ }^{\prime \prime} \mathrm{P}<0.05 \mathrm{vs}$. NC-siRNA. (E and F) After TNF- $\alpha$-treatment for $48 \mathrm{~h}$, the migratory ability of Eca109 cells was measured by a transwell migration assay, and the number of migrated cells in every field was counted. Magnification, $\mathrm{x} 400$. ${ }^{*} \mathrm{P}<0.05$. (G and $\mathrm{H}$ ) After TNF- $\alpha$-treatment for $24 \mathrm{~h}$, the expression of CyclinD1, Survivin and SOD-2 was measured by western blotting. "P<0.05 vs. respective NC-siRNA; ${ }^{2} \mathrm{P}<0.05$ vs. respective TNF- $\alpha+\mathrm{NC}$ siRNA. (I and J) Ecal09 cells transfected with control or NF- $\mathrm{kB}$ siRNA were treated with $20 \mathrm{ng} / \mathrm{ml}$ TNF- $\alpha$. After TNF- $\alpha$-treatment for $48 \mathrm{~h}$, the migratory ability of Eca109 cells was measured by a transwell migration assay, and the number of migrated cells in every field was counted. Magnification, $\mathrm{x} 400$. " $\mathrm{P}<0.05$. (K and L) After TNF- $\alpha$-treatment for $24 \mathrm{~h}$, the expression of NF- $\mathrm{kB}$, SOD-2, CyclinD1 and Survivin was detected by western blotting. Data are presented as the mean $\pm \mathrm{SD}$ of three independent experiments. ${ }^{*} \mathrm{P}<0.05$ vs. respective $\mathrm{NC}$-siRNA; ${ }^{\prime \prime} \mathrm{P}<0.05$ vs. respective TNF- $\alpha+$ NC siRNA. SOD-2, super dismutase [Mn], mitochondrial; TNF- $\alpha$, tumor necrosis factor- $\alpha$; NC, negative control; siRNA, small interfering RNA; p, phosphorylated.

by catalyzing the conversion of superoxide to hydrogen peroxide in cells $(12,23)$. Alterations in MnSOD enzymatic function or protein expression can have serious repercussions on mitochondrial activity, ultimately resulting in the development of an assortment of illnesses or participating in the appearance of malignant cellular phenotypes characterized by glycolytic metabolism (24). SOD-2 expression is upregulated in colorectal, lung, gastric/esophageal and cervical cancer cells compared with normal tissues $(25,26)$. In the present study, human ESCC samples were collected, and the expression of SOD-2 in ESCC as well as its role in overall survival was analyzed in patients with ESCC. High expression of SOD-2 was observed in human ESCC samples, which was associated with poor overall survival in patients with ESCC. The present results suggested that SOD-2 may function as an oncogene in ESCC. Several previous studies have shown that SOD-2 was upregulated in tongue squamous cell carcinoma, salivary adenoid cystic carcinoma, ovarian clear 

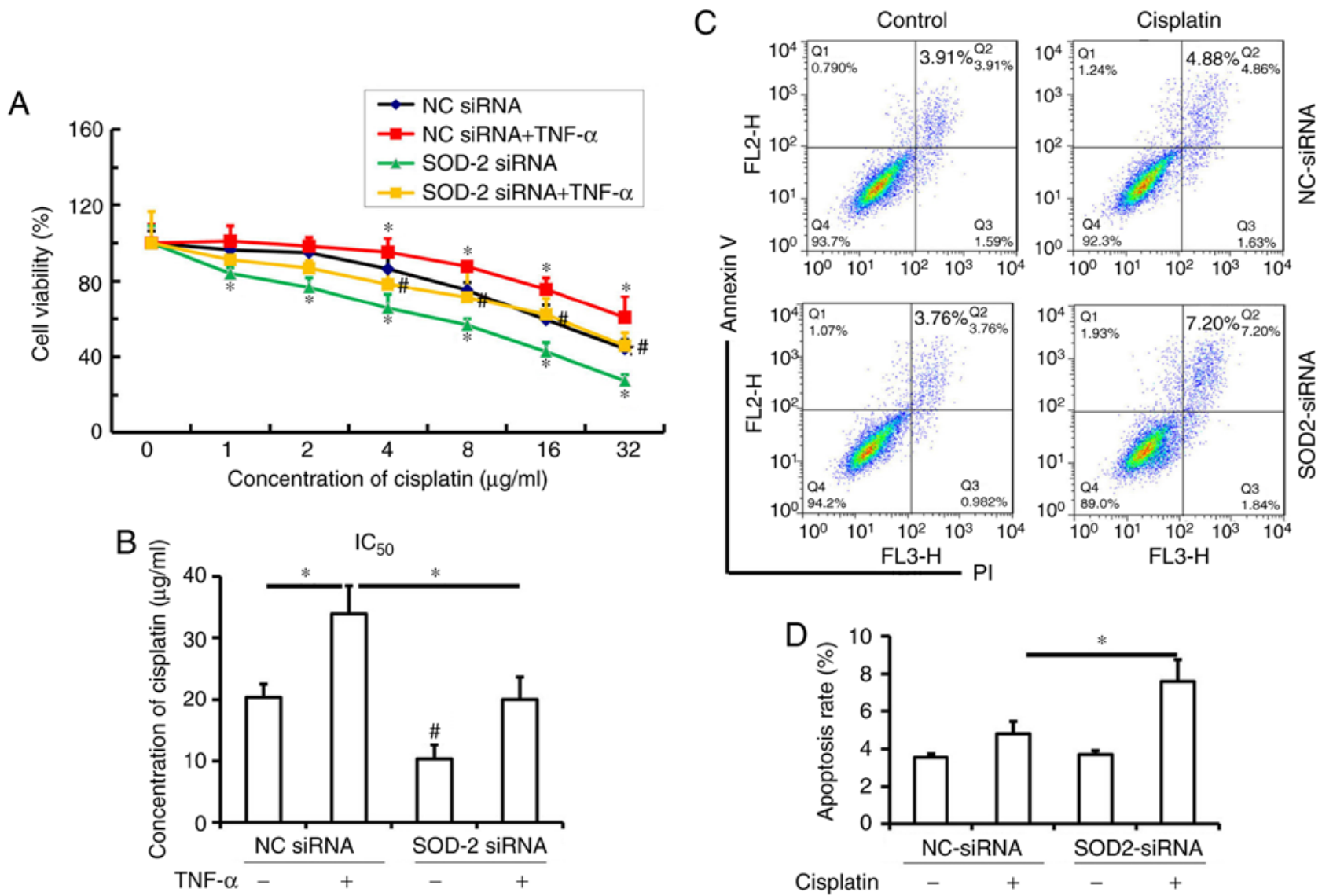

Figure 5. Effects of SOD-2 on the chemosensitivity of esophageal squamous cell carcinoma to cisplatin in vitro. (A) Eca109 cells were treated with or without TNF- $\alpha$ for $24 \mathrm{~h}$, then the cells transfected with NC-siRNA or SOD-2 siRNA were treated with different concentrations of cisplatin $(0-32 \mu \mathrm{g} / \mathrm{ml})$ for $24 \mathrm{~h}$. The cell viability was measured by a Cell Counting Kit- 8 assay. ${ }^{~} \mathrm{P}<0.05$ vs. respective NC-siRNA; ${ }^{\#} \mathrm{P}<0.05$ vs. respective TNF- $\alpha+\mathrm{NC}$ siRNA. (B) IC $\mathrm{C}_{50}$ of cisplatin in cells is presented. $\mathrm{P}<0.05 ;{ }^{*} \mathrm{P}<0.05$ vs. NC siRNA. (C and D) Eca109 cells transfected with control or SOD-2 siRNA were treated with $2 \mu \mathrm{g} / \mathrm{ml}$ cisplatin for $24 \mathrm{~h}$, and cell apoptosis was detected by flow cytometry with double staining of Annexin and PI. Data are presented as the mean \pm SD of three experiments. "P<0.05. SOD-2, super dismutase [Mn], mitochondrial; TNF- $\alpha$, tumor necrosis factor- $\alpha$; NC, negative control; siRNA, small interfering RNA; PI, propidium iodide.

cell carcinoma and lung cancer, which was associated with increased metastasis $(21,27,28)$. A positive correlation between TNF- $\alpha$ and SOD-2 expression was identified in human ESCC samples. Furthermore, a positive SOD-2 expression was significantly correlated with CyclinD1 and Survivin expression in human ESCC samples. The presented findings suggested that TNF- $\alpha /$ NF- $\mathrm{KB}$ might regulate SOD-2 expression associated with cell proliferation in ESCC.

TNF- $\alpha$, as a well-known transcriptional target of NF- $\mathrm{KB}$, has been reported to be an important regulator in tumor metastasis and proliferation $(29,30)$. Our previous study reported that the TNF- $\alpha$-mediated NF- $\kappa$ B pathway could upregulateSOD-2 expression, and contribute to EMT and migration in A549 cells (15). Therefore, it was necessary to examine whether high expression of SOD-2 contributes to cell proliferation using human ESCC cell lines Eca-109 and OE-21 cells in vitro. In the present study, it was demonstrated that SOD-2 expression in OE-21 was very low compared with that in Eca109 cells (data not shown). Therefore, one ESCC cell line, Eca109, was used in the present experiments. After cells were treated with a low concentration of TNF- $\alpha$ for $24 \mathrm{~h}$, it was observed that TNF- $\alpha$-induced cell proliferation was associated with upregulation of SOD-2 in Eca-109 cells. To further investigate if upregulation of SOD-2 plays a critical role in TNF- $\alpha$-induced cell proliferation in ESCC, SOD-2 expression was blocked by transfecting cells with SOD-2 siRNA. It was observed that blocking SOD-2 expression significantly inhibited TNF- $\alpha$-elevated cell viability and colony formation in ESCC cells, which indicated that upregulation of SOD-2 by TNF- $\alpha$ plays an important role in cell proliferation in ESCC. A previous study suggested that inflammatory cytokines, such as TNF- $\alpha$ and IL-6, could result in the subsequent expression of tumor-related genes, such as hypoxia-inducible factor 1- $\alpha$ and SOD-2 (31). In recent studies, NF- $\kappa \mathrm{B}$ si-RNA was applied to block the $\mathrm{NF}-\kappa \mathrm{B}$ pathway $(15,32)$. Blocking the NF- $\kappa \mathrm{B}$ pathway significantly inhibited TNF- $\alpha$-induced SOD-2 upregulation and cell migration in Eca109 cells. Therefore, the present results suggested that SOD-2 could be upregulated by the TNF- $\alpha / N F-\kappa B$ pathway in ESCC. Although siRNA was applied to inhibit the NF- $\kappa B$ pathway, future studies may aim to use specific inhibitors of the NF- $\mathrm{BB}$ pathway or specific TNF- $\alpha$ inhibitors to further validate this conclusion.

It has been shown that cisplatin-resistant lung cancer cells, regardless of the signaling pathway status, share a common parameter of increase in ROS (33). The ROS-activated GCN2-eIF2 $\alpha$-ATF4-xCT pathway contributes to mitochondrial dysfunction-enhanced cisplatin resistance in human 
gastric cancer cells (33). SOD-2, located in mitochondria, is essential for the removal of superoxide radicals and is critical for maintenance of cellular ROS homeostasis and bioenergetic balance (12). The present study aimed to investigate if SOD-2 is involved in cisplatin resistance to ESCC. It was observed that TNF- $\alpha$ induced cisplatin resistance in Eca109 cells, while transfecting with SOD-2 siRNA significantly increased the chemosensitivity of ESCC to cisplatin. Blocking SOD-2 could significantly enhance the ability of low concentrations of cisplatin to cause cell death in ESCC. The present results suggested that increased SOD-2 may play a critical role in cisplatin resistance in ESCC. Several previous studies have shown that overexpression of SOD-2 inhibits mtDNA oxidation from damage induced by high glucose, UV or acute ethanol exposure (34-36). These findings support that SOD-2 may play an important role in cisplatin resistance in ESCC during tumor chemotherapy.

In conclusion, it was determined that a higher expression of SOD-2 in human ESCC samples was associated with TNF- $\alpha$ expression and cell proliferation, as well as poor overall survival in patients with ESCC. SOD-2 upregulated by the TNF- $\alpha / N F-\kappa B$ pathway contributed to cell proliferation and played a critical role in cisplatin resistance in $\mathrm{ESCC}$ in vitro. A tumor-associated inflammation environment in the lung may induce high levels of SOD-2, which contributes to cisplatin resistance in ESCC. Therefore, SOD-2 may have a potent effect during cisplatin treatment to enhance drug resistance in ESCC and targeting SOD-2 may become a promising substitute for chemotherapy in ESCC.

\section{Acknowledgements}

The authors would like to thank Miss Shelly M Xie, an international student in School of International Education, Hebei Medical University, for assistance with editing the language.

\section{Funding}

The present study was supported by The National Natural Science Foundation of China (grant nos. 31570894, 81670939 and 81672706), The Foundation of Hebei Educational Committee (key program; grant no. ZD2015010), The Hebei Province Natural Science Foundation (grant no. H2015206208), The Hebei Province Natural Science Foundation for Youth (grant no. C2013206251), The Foundation of Hebei Educational Committee (grant no. SLRC2017045) and The Natural Science Foundation for Distinguished Young Scholars of Hebei Province (grant no. H2018206120 to SH and grant no. H2017206332 to ZJ).

\section{Availability of data and materials}

Not applicable.

\section{Authors' contributions}

JZ and MZ designed, performed and analyzed most of the experiments. BL provided technical support for the flow cytometer experiment and contributed to the flow cytometry analysis. XH helped perform the immunohistochemical staining and analysis. YL, QZ and WW helped collect the human samples and performed the statistical analysis of the human samples. PL provided intellectual support and helped design the cisplatin-resistance experiments. LX provided intellectual support and contributed to the design of the experiments. XZ and HS supervised and designed the study and experiments, analyzed data and co-wrote the manuscript. All authors read and approved the final manuscript.

\section{Ethics approval and consent to participate}

The present study has been approved by the Ethics Committee of Hebei Medical University (Hebei, China), and the handling of the information and specimens collected was conducted in accordance with their ethical and legal standards. The patients, who agreed to the use of their samples in scientific research, all provided written informed consent.

\section{Patient consent for publication}

Not applicable.

\section{Competing interests}

The authors declare that they have no competing interests.

\section{References}

1. Chen W, Zheng R, Baade PD, Zhang S, Zeng H, Bray F, Jemal A Yu XQ and He J: Cancer statistics in China, 2015. CA Cancer J Clin 66: 115-132, 2016.

2. Messager M, Warlaumont M, Renaud F, Marin H, Branche J, Piessen G and Mariette C: Recent improvements in the management of esophageal anastomotic leak after surgery for cancer. Eur J Surg Oncol 43: 258-269, 2017.

3. Zeng H, Zheng R, Guo Y, Zhang S, Zou X, Wang N, Zhang L, Tang J, Chen J, Wei K, et al: Cancer survival in China, 2003-2005: A population-based study. Int J Cancer 136: 1921-1930, 2015.

4. Zhou P, Zhang R, Wang Y, Xu D, Zhang L, Qin J, Su G, Feng Y, Chen $\mathrm{H}$, You S, et al: Cepharanthine hydrochloride reverses the mdr1 (P-glycoprotein)-mediated esophageal squamous cell carcinoma cell cisplatin resistance through JNK and p53 signals. Oncotarget 8: 111144-111160, 2017.

5. Liu T, Li R, Zhao H, Deng J, Long Y, Shuai MT, Li Q, Gu H, Chen YQ and Leng AM: eIF4E promotes tumorigenesis and modulates chemosensitivity to cisplatin in esophageal squamous cell carcinoma. Oncotarget 7: 66851-66864, 2016.

6. Siddik ZH: Cisplatin: Mode of cytotoxic action and molecular basis of resistance. Oncogene 22: 7265-7279, 2003.

7. Fang C, Chen YX, Wu NY, Yin JY, Li XP, Huang HS, Zhang W, Zhou HH and Liu ZQ: MiR-488 inhibits proliferation and cisplatin sensibility in non-small-cell lung cancer (NSCLC) cells by activating the eIF3a-mediated NER signaling pathway. Sci Rep 7: 40384, 2017.

8. Li M, Chen W, Zhang H, Zhang Y, Ke F, Wu X, Zhang Y, Weng M, Liu Y and Gong W: MiR-31 regulates the cisplatin resistance by targeting Src in gallbladder cancer. Oncotarget 7: 83060-83070, 2016.

9. Wangpaichitr M, Sullivan EJ, Theodoropoulos G, Wu C, You M, Feun LG, Lampidis TJ, Kuo MT and Savaraj N: The relationship of thioredoxin-1 and cisplatin resistance: Its impact on ROS and oxidative metabolism in lung cancer cells. Mol Cancer Ther 11: 604-615, 2012.

10. Green DR and Reed JC: Mitochondria and apoptosis. Science 281: 1309-1312, 1998.

11. Trachootham D, Lu W, Ogasawara MA, Nilsa RD and Huang P: Redox regulation of cell survival. Antioxid Redox Signal 10: 1343-1374, 2008.

12. Miriyala S, Holley AK and St Clair DK: Mitochondrial superoxide dismutase-signals of distinction. Anticancer Agents Med Chem 11: 181-190, 2011. 
13. Kienhöfer J, Häussler DJ, Ruckelshausen F, Muessig E, Weber K, Pimentel D, Ullrich V, Bürkle A and Bachschmid MM: Association of mitochondrial antioxidant enzymes with mitochondrial DNA as integral nucleoid constituents. FASEB J 23: 2034-2044, 2009.

14. Zhou J and Du Y: Acquisition of resistance of pancreatic cancer cells to 2-methoxyestradiol is associated with the upregulation of manganese superoxide dismutase. Mol Cancer Res 10: 768-777, 2012.

15. Yi L, Shen H, Zhao M, Shao P, Liu C, Cui J, Wang J, Wang C, Guo N, Kang L, et al: Inflammation-mediated SOD-2 upregulation contributes to epithelial-mesenchymal transition and migration of tumor cells in aflatoxin G1-induced lung adenocarcinoma. Sci Rep 7: 7953, 2017.

16. Chung-man Ho J, Zheng S, Comhair SA, Farver $\mathrm{C}$ and Erzurum SC: Differential expression of manganese superoxide dismutase and catalase in lung cancer. Cancer Res 61: 8578-8585, 2001.

17. Kinugasa H, Whelan KA, Tanaka K, Natsuizaka M, Long A, Guo A, Chang S, Kagawa S, Srinivasan S, Guha M, et al: Mitochondrial SOD2 regulates epithelial-mesenchymal transition and cell populations defined by differential CD44 expression. Oncogene 34: 5229-5239, 2015.

18. Rice TW, Ishwaran H, Hofstetter WL, Kelsen DP Apperson-Hansen C and Blackstone EH; Worldwide Esophageal Cancer Collaboration Investigators: Recommendations for pathologic staging (pTNM) of cancer of the esophagus and esophagogastric junction for the 8th edition AJCC/UICC staging manuals. Dis Esophagus 29: 897-905, 2016.

19. Rice TW, Gress DM, Patil DT, Hofstetter WL, Kelsen DP and Blackstone EH: Cancer of the esophagus and esophagogastric junction-Major changes in the American Joint Committee on Cancer eighth edition cancer staging manual. CA Cancer J Clin 67: 304-317, 2017.

20. Liu C, Shen H, Yi L, Shao P, Soulika AM, Meng X, Xing L, Yan $\mathrm{X}$ and Zhang $\mathrm{X}$ : Oral administration of aflatoxin $\mathrm{G}_{1}$ induces chronic alveolar inflammation associated with lung tumorigenesis. Toxicol Lett 232: 547-556, 2015.

21. Chang B, Yang H, Jiao Y, Wang K, Liu Z, Wu P, Li S and Wang A: SOD2 deregulation enhances migration, invasion and has poor prognosis in salivary adenoid cystic carcinoma. Sci Rep 6: 25918, 2016.

22. Livak KJ and Schmittgen TD: Analysis of relative gene expression data using real-time quantitative PCR and the 2(-Delta Delta C(T)) method. Methods 25: 402-408, 2001

23. Shen H, Liu J, Wang Y, Lian H, Wang J, Xing L, Yan X, Wang J and Zhang X: Aflatoxin G1-induced oxidative stress causes DNA damage and triggers apoptosis through MAPK signaling pathway in A549 cells. Food Chem Toxicol 62: 661-669, 2013.

24. Miao L and St Clair DK: Regulation of superoxide dismutase genes: Implications in disease. Free Radic Biol Med 47: 344-356, 2009.
25. Johnson F and Giulivi C: Superoxide dismutases and their impact upon human health. Mol Aspects Med 26: 340-352, 2005.

26. Kinnula VL and Crapo JD: Superoxide dismutases in malignant cells and human tumors. Free Radic Biol Med 36: 718-744, 2004

27. Liu Z, Li S, Cai Y, Wang A, He Q, Zheng C, Zhao T, Ding X and Zhou X: Manganese superoxide dismutase induces migration and invasion of tongue squamous cell carcinoma via $\mathrm{H} 2 \mathrm{O} 2$-dependent Snail signaling. Free Radic Biol Med 53: 44-50, 2012.

28. Hemachandra LP, Shin DH, Dier U, Iuliano JN, Engelberth SA, Uusitalo LM, Murphy SK and Hempel N: Mitochondrial superoxide dismutase has a protumorigenic role in ovarian clear cell carcinoma. Cancer Res 75: 4973-4984, 2015.

29. Kitakata H, Nemoto-Sasaki Y, Takahashi Y, Kondo T, Mai M and Mukaida N: Essential roles of tumor necrosis factor receptor p55 in liver metastasis of intrasplenic administration of colon 26 cells. Cancer Res 62: 6682-6687, 2002.

30. Tomita Y, Yang X, Ishida Y, Nemoto-Sasaki Y, Kondo T, Oda M, Watanabe G, Chaldakov GN, Fujii C and Mukaida N: Spontaneous regression of lung metastasis in the absence of tumor necrosis factor receptor p55. Int J Cancer 112: 927-933, 2004.

31. Atsumi T, Singh R, Sabharwal L, Bando H, Meng J, Arima Y, Yamada M, Harada M, Jiang JJ, Kamimura D, et al: Inflammation amplifier, a new paradigm in cancer biology. Cancer Res 74: 8-14, 2014.

32. Shao P, Guo N, Wang C, Zhao M, Yi L, Liu C, Kang L, Cao L, Lv P, Xing L, et al: Aflatoxin $\mathrm{G}_{1}$ induced TNF- $\alpha$-dependent lung inflammation to enhance DNA damage in alveolar epithelial cells. J Cell Physiol 234: 9194-9206, 2019

33. Wang SF, Chen MS, Chou YC, Ueng YF, Yin PH, Yeh TS and Lee HC: Mitochondrial dysfunction enhances cisplatin resistance in human gastric cancer cells via the ROS-activated GCN2-eIF2 $\alpha$-ATF4-xCT pathway. Oncotarget 7: 74132-74151, 2016.

34. Takai D, Park SH, Takada Y, Ichinose S, Kitagawa M and Akashi M: UV-irradiation induces oxidative damage to mitochondrial DNA primarily through hydrogen peroxide: Analysis of 8-oxodGuo by HPLC. Free Radic Res 40: 1138-1148, 2006.

35. Larosche I, Letteron P, Berson A, Fromenty B, Huang TT, Moreau R, Pessayre D and Mansouri A: Hepatic mitochondrial DNA depletion after an alcohol binge in mice: Probable role of peroxynitrite and modulation by manganese superoxide dismutase. J Pharmacol Exp Ther 332: 886-897, 2010.

36. Madsen-Bouterse SA, Zhong Q, Mohammad G, Ho YS and Kowluru RA: Oxidative damage of mitochondrial DNA in diabetes and its protection by manganese superoxide dismutase. Free Radic Res 44: 313-321, 2010. 